\title{
COMPONENTES MINERAIS E ORGÂNICOS DE ALGUMAS VARIEDADES DE FEIJÃO (Phaseolus vulgaris, L.)
}

\author{
HOMERo Fonseca ** \\ José R. SARruge \\ José D. P. ARzolla
}

\section{RESUMO}

Neste trabalho foi estudada a composição de 14 variedades de feijão de mesa comumente encontrados em nosso mercado. Os teores médios encontrados foram: umidade $11,6 \%$, proteina, $21,5 \%$, lipideos $1,3 \%$, polissacarideos $45,2 \%$ açúcares solúveis $4,7 \%$, cinzas $3,9 \%$.

Os aminoácidos livres também identificados e dosados variaram de 610 a $1442 \mathrm{mg} / 100 \mathrm{~g}$. O conteúdo médio dos macronutrientes minerais, em percentagem foram: fósforo 0,17 , potássio 1,88 , cálcio 0,23 , magnésio 0,24 e enxofre 2,23. Os valores médios encontrados para os micronutrientes, em ppm foram: boro 24,3 , zinco 47,9 , cobre 17,4 , molibdênio 0,11 , ferro 330,8 e manganês 17,6 . Houve grande variação no teor de boro $(14,2$ a $73,8 \mathrm{ppm})$, molibdênio $(0,02$ a $0,32 \mathrm{ppm}) \mathrm{e}$ ferro (167,9 a $598,6 \mathrm{ppm}$ ) tendo-se mantido os demais, entre limites mais estreitos.

Pelos resultados encontrados o feijão fol considerado uma boa fonte de carbohidratos e minerais (macro e micronutrientes) e uma fonte relativamente boa de proteina.

\section{INTRODUÇAOO}

O feijão tem sido um dos alimentos básicos do brasileiro e constituise, para grande parte da população, a maior e às vezes, única fonte apreciável de proteínas e de outro composto essenciais ao organismo tais como as vitaminas $B_{1}, B_{2}$ e niacina, sais minerais de potássio, fósforo, enxofre, sódio, cálcio, magnésio, ferro, etc.

- Entregue para publicação em 27/12/1974.

** Depto de Tecnologia Rural, E. S. A. «Luiz de Queiroz», USP.

*** Dept9 de Química, E. S. A. «Luiz de Queiroz», USP.

**** Depto de Química, E. S. A. «Luiz de Queiroz», USP, falecido em 08/11/1970. 
Muitas são as variedades de feijão consumidas no Brasil, e a cada ano que passa novas variedades vão surgindo. A literatura brasileira é abundante de citações de autores e de tabelas de composição estrangeiras, com resultados de análises de variedades exóticas de feijão, também cultivadas em solo e clima diferentes do nosso.

Dentre esses podemos citar as tabelas da FAO (1949), do INCAP-ICNND (1961), do USDA (1964) e dos DOCUMENTA GEIGY. Todas estas tabelas trazem apenas valores médios para os componentes nutricionais do feijão.

Dentre os trabalhos realizados em nosso país e com variedades nossas podemos citar os trabalhos de PAULA (1952) com análise percentual de dez variedades nacionais. BETHLEMet al. (1953) analisaram 50 variedades de feijão inclusive variedades exóticas e também soja. Pouca atenção foi dada à determinação à uma análise mais completa no que tange aos elementos minerais e mesmo à uma análise quantitativa dos aminoácidos.

Algumas tentativas neste sentido foram feitas por MATOS Jr. (1952, 1955), FONSECA et al. (1964), ARZOLLA \& FONSECA (1970) e FONSECA \& ARZOLLA (1970) que analisaram aminoácidos e açúcares em feijões.

LIMA (1970) estudou a composição de dois tipos de feijão, (Phasieolus vulgaris e Vigna sinensis ENDL.) principalmente quanto ao seu valor protico (aminoácidos) e MORAES \& ANGELUCCI (1971) que estudaram doze variedades de feijão, quanto à sua composição centezimal, alguns minerais (ferro, fósforo, cálcio e magnésio) e a composição da proteína, em aminoácidos.

O objetivo do presente trabalho foi dar continuidade aos anteriores, procurando analisar os constituintes orgânicos, como, nitrogênio total, nitrogênio não proteico, proteína, lipídeos, polissacarídeos, açúcares solúveis e cinzas, e os elementos minerais fósforo, potássio, cálcio, magnésio, enxofre, boro, zinco, cobre, molibdênio, ferro e manganês de 14 variedades de feijão de mesa, bem como os aminoácidos livres de 8 delas.

\section{MATERIAL E MÉTODOS}

\section{Material}

O material constou de amostras de feijão adquiridos no comércio local.

\section{Métodos químicos}

Umidade: segundo a AOAC (1965);

Nitrogênio total: pela técnica de micro-Kjeldhal descrita em MALAVOLTA (1957);

Proteina: multiplicando-se o valor do nitrogênio total pelo fator 6,25; Aminoácidos livres: conforme ARZOLLA \& FONSECA (1966); 
Polissacarídeos: pela diferença entre os glucideos totais e açúcares solúveis. Os glucídeos totais foram determinados por hidrólise ácida direta (AOAC, 1965) e posterior dosagem dos açúcares redutores pelo método de LANE \& EYNON (1923);

Açúcares solúveis: de acordo com FONSECA \& ARZOLLA (1965);

Lipídeos: de acordo com a AOAC (1695);

As determinações dos elementos minerais foram feitas no material seco em estufa de circulação forçada de ar, à temperatura de $70^{\circ} \mathrm{C}$ e moido em moinho Wiley, peneira n. ${ }^{\circ}$ 20. Deste material foi feito um extrato nítrico-perclórico e as análises efetuadas em alíquotas do mesmo.

Os métodos usados foram os seguintes:

Fósforo: vanado-molibidato de amônio;

Potássio: fotometria de chama;

Cálcio: precipitação com ácido oxálico e titulação com permanganato de potássio;

Magnésio: tiazol amarelo;

Enxofre: gravimetria com sulfato de bário;

Boro: curcumina;

Cobre: carbamato

Zinco: zincon;

Molibdênio: tiocianato;

Ferro: orto-fenantrolina;

Manganês: oxidação com meta-periodato.

Estes métodos estão descritos em SARRUGE \& HAAG (1974).

\section{Métodos estatísticos}

A análise de correlação foi feita segundo GOMES (1973).

\section{RESULTADOS E DISCUSSÃO}

Os resultados das análises químicas são os encontrados nos QUADROS de n. ${ }^{\text {os }} 1$ a 4 e o resultado das correlações, no Quadro 5.

O conteúdo de umidade esteve ao redor de $11,6 \%$ e o teor de cinzas, cerca de $3,9 \%$.

O conteúdo de proteinas variou de $18,33 \%$ no pintado a $26,56 \%$ no preto, com média de $21,54 \%$. O conteúdo médio dos lipídeos foi de 1,3\% com va- 
riação de $0,9 \%$ no rosado ranésia a $1,8 \%$ no rosinha. Quanto aos polissacarídeos a média foi de $45,20 \%$ com extremos de $38,82 \%$ no rosado ranésia e $49,77 \%$ no preto. Os açúcares solúveis variaram de $4,15 \%$ a $5,37 \%$.

Estes resultados indicam que o feijão é uma boa fonte de carbohidratos e relativamente boa de proteinas. O conteúdo de lipídeos é bastante baixo não sendo o feijão considerado como fonte destes nutrientes.

0 conteúdo de amioácidos livres constitui parcela não desprezível, tendo variado de 610,5 a $1442,7 \mathrm{mg} / 100 \mathrm{~g}$, tendo predominado os ácidos glutâmico, aspártico, alanina e lisina. Os aminoácidos livres têm sua importância pois são prontamente absorvidos pelo organismo.

Considerando-se as necessidades diárias do homem (NATIONAL RESEARCH COUNCIL, 1964), o feijão pode ser considerado também como boa fonte tanto dos macro como dos micronutrientes.

Alguns elementos apresentaram uma variação maior, entre os feijões, e dentre eles destacam-se o boro (de 14,2 a $73,8 \mathrm{ppm}$ ), o molibdênio (de 0,02 a $0,32 \mathrm{ppm}$ ), o ferro (de 167,9 a $598,6 \mathrm{ppm}$ ). Os demais elementos variaram entre limites mais estreitos.

A correlação calculada entre os elementos minerais e os componentes orgânicos e também cinzas mostrou-se significativa ao nível de $1 \%$ de probabilidade apenas entre nitrogênio e polissacarídeos com $\mathbf{r}=-0,75$, negativamente portanto. 0 teor de magnésio mostrou correlação positiva $(r=0,54)$ com o teor de cinzas, porém ao nível de $5 \%$ de probabilidade. As demais correlações (constantes do QUADRO 5, não foram significativas, conquanto algumas se aproximassem do nível de significância a $5 \%$.

Os resultados por nós obtidos concordam em parte com os encontrados por MORAES \& ANGELUCCI (1971) nas mesmas variedades estudadas neste e naquele trabalho. As diferenças, cremos, devam ser creditadas às diferentes condições de solo, clima, adubação, etc. $\mathrm{O}$ mesmo pode ser dito com relação às tabelas pois elas representam valores médios de feijões de variedades certamente diferente das nossas e cultivadas também em outras condições.

\section{CONCLUSÓES}

Conclui-se, pelos resultados obtidos, que o feijão pode ser considerado como uma fonte de carbohidratos, minerais (macro e micronutrientes) e como uma fonte relativamente boa de proteinas.

\section{SUMMARY}

ORGANIC AND MINERAL COMPONENTS OF SOME BRAZILIAN BEANS (PHASEOLUS VULGARIS L.).

In the present work the organic and mineral composition of 14 varietis of beans (Phaseolus vulgaris L.) commonly found in our markets were 
studied. The average value for misture was $11.6 \%$, protein $21.5 \%$, lipids $1.3 \%$, polysaccharides $45.2 \%$, soluble sugars $4.7 \%$ and ash $3.9 \%$. Free amino ácido evere identified and yielded from 610 to $1442 \mathrm{mg} / 100 \mathrm{~g}$.

The mean values for the mineral macronutrients were (in \%): phosphate 0.17 , potassium 1.88, calcium 0.23 , magnesium 0.24 and sulphur 2.23. The average contents of micronutrients were (in ppm): boron 24.3, zinc 47.9, copper 174, molibdenium 0.11 , iron 330.8 and manganese 17.6 .

It was found a great variation in the boron $(14.2-73.8)$, molibdenium $(002-0,32)$ and iron $(167.9-598.6 \mathrm{ppm})$ contents. All other components showed a small variation.

It was concluded that common beans can be considered a good source of carbohydrates and minerals (macro and micronutrients), and a fairly good source of protein.

\section{LITERATURA CITADA}

A. O A. C., 1965 - «Official Methods of Analysis» Association of Official Agricultural Chemists. $1^{\text {th }}$ edition. Washington, D. C.

ARZOLLA, J. D. P. \& H. FONSECA, 1966 - Cromatografia de Amino-ácidos. Boletím Didático n. ${ }^{\circ}$ 14, ESALQ-USP, Piracicaba. 54 pp.

ARZOLLA, J. D. P. \& H. FONSECA, 1970 - Aminoácidos livres do feijão 60 Dias (Phaseolus vulgaris L.). Anais da ESALQ, XXVII : 191-197.

BETHLEM, M. L. B., H. P. NEVES, F. MALOUK \& M. TAVEIRA, 1953 - Composição centesimal de 50 variedades de feijões existentes no Brasil. Rev. Bras. de Farm. ANO XXXIV (7) : 260.

DOCUMENTA GEIGY, (s. d.) - «Nutritional Values». Documenta Geigy Scientific Tables, General Practitioner Series. Geigy Pharmaceutical Co. Ltd. Manchester, England. $40 \mathrm{pp}$.

FAO, 1949 - Food Composition Tables for International Use. Food and Agriculture Organization of the United Nations, Rome.

FONSECA, H., J. D. P. ARZOLLA \& J. R. SARRUGE, 1964 - Aminoácidos livres de três variedades de feijão (Phaseolus vulgaris L.) do Paraná. Anais do I Simpósio Brasileiro de Cromatografia. Boletim da Universidade do Paraná (Curitiba), $21: 45-50$.

FONSECA, H. \& J. D. P. ARZOLLA, 1970 - Ocorrência e dosagem de açúcares Didático n. $\cdot 7$, ESALQ-USP, Piracicaba. $19 \mathrm{pp}$.

FONSECA, H. \& J. D. P. AROLLA, 1970 - Ocorrência e dosagem de açúcares em algumas variedades brasileiras de feijão (Phaseolus vulgaris L.). Anais da ESALQ, XXVII : 199-203.

GOMES, F. P., 1973 - «Curso de Estatística Experimental». 5.4 Ed. Livraria Nobel S. Paulo.

INCAP - ICNND, 1961 - Tabla de Composición de Alimentos Para Uso en América Latina. Instituto de Nutrición de Centro America y Panamá, Guatemala, y Comitê Interdepartamental de Nutrición para la Defesa Nacional, Bethesda, Md. EUA.

LANE, J. H. \& L. EYNON, 1923 - Determinations of reducing sugars by Fehling's solution with methylene b'ue indicator. J. Soc. Chem. Ind. 42:32T, 463T. 
LIMA, B., 1970 - Estudo bromatológico de feijões (Phaseolus vulgaris L. e Vigna sinensis ENDL.) nas condições que são vulgarmente consumidos. Fac. de Ciências Farmacêuticas, U. S. P., S. Paulo. Tese, 38 pp.

MalaVolta, E., 1957 - Práticas de Química Orgânica e Biológica. C. A. L. Q. - ESALQ - USP. - Piracicaba, SP.

MATOS, Jr., A. G., 1952 - Análise do feijão mulatinho. Rev. Bras. de Med., IX, 6.

MATOS Jr., A. G., 1955 - Aminoácidos do feijão macassar. Anais Soc. Biol. Pernambuco - Recife, $13: 235-238$.

MORAES, R. M. \& E. ANGELUCCI, 1971 - Chemiach composition and amino acid contents of Brazilian beans (Phaseolus vulgaris). J. Food Sci., 36(3) : 493-4.

NATIONAL RESEARCH COUNCL, 1964 - Recommended Dietary Allowances. Report of the Food and Nutrition Board, National Academy of Sciences. $6^{\text {th }}$ ed. Publication 1146, Washington, D. C.

PAULA, R. D. G., 1952 - «Alimentos». Vol. II. Livraria Editora Casa do Estudante do Brasil, Rio de Janeiro.

SARRUGE, J. R. \& H. P. HAAG, 1974 - «Análises Químicas em Plantas». E. S. A. «Luiz de Queiroz», - USP - Piracicaba, SP. Distribuição, Livroceres Ltda. Piracicaba, SP.

U. S. D. A., 1964 - Nutritive value of foods. Home and Garclen Bulletin n. ${ }^{\circ} \mathbf{7 2}$, U. S. Depto. of Agriculture, Washington, D. C. 
Quadro I: Composicão percentual de 14 variedades de feijão.

\begin{tabular}{lcccccccc}
\hline Foijão & \multicolumn{2}{c}{ Umidade } & $\begin{array}{c}\text { Nitrogênio } \\
\text { Total }\end{array}$ & Proteina & Lipídeos & Açúcares & Polissacar. Cinzes & Indeterm. \\
\hline Rosinha & 12,16 & 3,02 & 18,87 & 1,80 & 4,15 & 45,85 & 4,50 & 12,67 \\
Bico de Ouro & 11,03 & 3,05 & 19,06 & 1,20 & 4,21 & 49,45 & 3,30 & 11,72 \\
Jalo & 11,53 & 3,52 & 22,00 & 1,40 & 5,22 & 40,18 & 3,20 & 16,47 \\
Preto & 11,66 & 4,25 & 26,56 & 1,50 & 4,38 & 38,82 & 4,00 & 13,08 \\
Mulatinho & 10,88 & 3,75 & 23,44 & 1,30 & 4,33 & 44,37 & 5,00 & 10,68 \\
Roxinho & 12,00 & 3,80 & 23,75 & 1,10 & 5,26 & 42,35 & 3,40 & 12,14 \\
Pintado & 11,00 & 2,93 & 18,33 & 1,70 & 5,37 & 47,26 & 3,80 & 12,54 \\
Pintadão & 12,00 & 2,94 & 18,37 & 1,40 & 5,00 & 48,76 & 4,40 & 10,83 \\
Preto Paraná & 13,00 & 3,23 & 20,19 & 1,40 & 4,72 & 45,28 & 3,90 & 11,51 \\
Argentino & 13,00 & 3,80 & 23,75 & 1,20 & 4,94 & 40,51 & 4,00 & 12,60 \\
Mulato Argentino & 10,00 & 3,75 & 23,44 & 1,20 & 4,83 & 43,71 & 3,20 & 13,62 \\
Rosado Ranésia & 11,00 & 3,17 & 19,81 & 0,90 & 5,23 & 49,77 & 4,20 & 10,09 \\
Opaco & 12,00 & 3,52 & 22,00 & 1,20 & 4,10 & 48,40 & 4,10 & 8,20 \\
Lustroso & 12,00 & 3,52 & 22,00 & 1,40 & 4,33 & 48,17 & 3,80 & $\mathbf{8 , 3 0}$ \\
\hline médias & 11,66 & 3,45 & 21,54 & 1,30 & 4,72 & 45,20 & 3,91 & \\
\hline
\end{tabular}

Quadro II: Conteúdo de aminoácidos livres em 8 variedades de feijão (em $\mathrm{mg} / 100 \mathrm{~g}$ ).

\begin{tabular}{|c|c|c|c|c|c|c|c|c|}
\hline \multirow{2}{*}{ Aminofacidos } & \multicolumn{8}{|c|}{ FEIJŌES } \\
\hline & $\begin{array}{l}\text { Rosado } \\
\text { Ranésia }\end{array}$ & Pintadão & Pintado & Roxinho & $\begin{array}{l}\text { Bico de } \\
\text { Ouro }\end{array}$ & Argentino & D Lustroso & Mula- \\
\hline Ácido Aspartico & 66,3 & 99,2 & 62,4 & 52,4 & 89,0 & 101,6 & 65,0 & 144,0 \\
\hline Serina & 16,9 & 24,0 & 12,8 & 18,2 & 18,5 & 9,0 & 19,0 & 32,0 \\
\hline Acido Glutámico & 131,0 & 132,0 & 131,2 & 123,1 & 139,0 & 194,0 & 184,0 & 232,0 \\
\hline Glicina & 15,6 & 12,8 & 14,4 & 15,6 & 16,0 & 12,0 & 19,0 & 17,0 \\
\hline Asparagina & 40,3 & 48,0 & 30,4 & 32,5 & 51,5 & 42,0 & 39,0 & 64,0 \\
\hline Lisina & 87,1 & 52,8 & 70,4 & 84,5 & 110,0 & 110,0 & 95,0 & 143,0 \\
\hline Histidina & 45,5 & 22,4 & 20,8 & 63,7 & 48,5 & 136,0 & 67,0 & 187,0 \\
\hline Arginina & 139,1 & 54,4 & 20,8 & 146,0 & 117,0 & 30,0 & 79,0 & 138,0 \\
\hline Treonina & 11,7 & 6,4 & 1,6 & - & 14,0 & 14,0 & - & 25,8 \\
\hline Alanina & 139,1 & 145,6 & 166,4 & - & 150,0 & 194,0 & 148,0 & 194,0 \\
\hline B-Alanina & 20,8 & 14,4 & - & - & 20,0 & 14,0 & 16,5 & 23,4 \\
\hline $\mathrm{NH}_{2}$ But'́rico & 11,7 & 11,2 & 38,4 & 13,1 & 15,0 & 68,0 & 46,0 & 88,0 \\
\hline Triptofano & 42,9 & 27,2 & 14,4 & 26,2 & 39,5 & 43,0 & 35,0 & 57,0 \\
\hline Met. + Valina & 22,1 & 16,0 & 17,6 & 13,1 & 16,5 & 19,0 & 17,8 & 29,0 \\
\hline Fenilalanina & 2,6 & - & 9,0 & 5,2 & 4,0 & 8,0 & 9,5 & 11,5 \\
\hline Leucina & 44,2 & 19,2 & 10,2 & 16,9 & 28,0 & 18,0 & 29,0 & 57,0 \\
\hline Total & 836,9 & 685,6 & 620,8 & 610,5 & 866,51 & $1.012,6$ & 873,4 & $1.442,7$ \\
\hline
\end{tabular}


Quadro 3. Macronutrientes minerais em 14 variedades de feijão (em percentagem).

\begin{tabular}{lccccr}
\hline Feijão & Fósforo & Potássio & Cálcio & Magnésio & Enxofre \\
\hline Rosinha & 0,16 & 1,75 & 0,27 & 0,26 & 1,80 \\
Bico de Ouro & 0,11 & 1,75 & 0,20 & 0,19 & 2,00 \\
Jalo & 0,15 & 1,75 & 0,20 & 0,22 & 5,70 \\
Preto & 0,20 & 1,05 & 0,17 & 0,26 & 1,90 \\
Mulatinho & 0,20 & 1,95 & 0,22, & 0,24 & 2,00 \\
Roxinho & 0,14 & 1,85 & 0,17 & 0,22 & 2,50 \\
Pintado & 0,18 & 1,85 & 0,17 & 0,22 & 2,10 \\
Pintadão & 0,19 & 2,00 & 0,30 & 0,23 & 1,60 \\
Preto Paraná & 0,12 & 1,75 & 0,27 & 0,25 & 1,80 \\
Argentino & 0,17 & 1,95 & 0,25 & 0,29 & 2,00 \\
Mulato Argentino & 0,19 & 1,85 & 0,27 & 0,23 & 2,10 \\
Rosado Ranésia & 0,18 & 1,85 & 0,27 & 0,28 & 1,90 \\
Opaco & 0,18 & 1,95 & 0,77 & 0,24 & 2,00 \\
Lustroso & 0,19 & 1,95 & 0,30 & 0,22 & 1,80 \\
\hline médias & 0,17 & 1,88 & 0,27 & 0,24 & 2,23 \\
\hline
\end{tabular}

Quadro 4. Micronutrientes minerais em 14 variedades de feijão (em partes por milhão) .

\begin{tabular}{|c|c|c|c|c|c|c|}
\hline Feijão & Boro & Zinco & Cobre & Molibdênio & Ferro & Manganês \\
\hline Rosinha & 22,7 & 41,2 & 25,4 & 0,04 & 229,3 & 25,8 \\
\hline Bico de Ouro & 20,5 & 36,2 & 19,5 & 0,10 & 244,5 & 16,4 \\
\hline Jalo & 17,8 & 38,2 & 21,6 & 0,10 & 167,9 & 8,2 \\
\hline Preto & 19,9 & 43,1 & 19,5 & 0,08 & 551,1 & 17,6 \\
\hline Mulatinho & 22,0 & 36,3 & 19,5 & 0,12 & 193,4 & 17,6 \\
\hline Roxinho & 17,7 & 40,2 & 8,4 & 0,05 . & 584,0 & 18,8 \\
\hline Pintado & 14,2 & 48,0 & 21,9 & 0,01 & 175,2 & 23,6 \\
\hline Pintadão & 22,0 & 35,3 & 7,8 & 0,08 & 251,8 & 21,2 \\
\hline Preto Paraná & 23,4 & 85,3 & 15,6 & 0,07 & 580,3 & 21,1 \\
\hline Argentino & 73,8 & 45,1 & 28,3 & 0,19 & 262,8 & 14,1 \\
\hline Mulato Argentino & 21,3 & 40,2 & 8,7 & 0,07 & 324,8 & 15,9 \\
\hline Rosado Ranésia & 23,3 & 64,9 & 20,4 & 0,03 & 598,6 & 18,8 \\
\hline Opaco & 19,9 & 57,8 & 15,9 & 0,31 & 211,7 & 11,7 \\
\hline Lustroso & 22,0 & 59,6 & 10,5 & 0,30 & 255,5 & 15,9 \\
\hline médias & 24,3 & 47,9 & 17,4 & 0,11 & 330,8 & 17,6 \\
\hline
\end{tabular}


Quadro 5. Coeficiente de correlação ( $r$ ) entre o teor de alguns minerais e frações importantes do feijão.

\begin{tabular}{lccccc}
\hline $\begin{array}{l}\text { Elementos } \\
\text { Minerais }\end{array}$ & Proteínas & Lipídeos & $\begin{array}{c}\text { Açúcares } \\
\text { Solúveis }\end{array}$ & $\begin{array}{c}\text { Polissa- } \\
\text { carídeos }\end{array}$ & Cinzas \\
\hline Nitrogênio & - & $-0,24$ & $-0,10$ & $-0,75++$ & $-0,10$ \\
Fósforo & 0,29 & 0,10 & $-0,014$ & $-0,03$ & 0,46 \\
Potássio & 0,50 & $-0,09$ & $-0,14$ & $-0,14$ & 0,42 \\
Cálcio & $-0,05$ & $-0,18$ & $-0,42$ & 0,38 & 0,19 \\
Magnésio & 0,27 & $-0,10$ & 0,02 & $-0,26$ & $0,54+$ \\
Enxôfre & 0,13 & 0,01 & 0,37 & $-0,45$ & $-0,48$ \\
Boro & 0,24 & $-0,21$ & 0,06 & $-0,32$ & 0,12 \\
Zinco & $-0,16$ & $-0,15$ & 0,04 & 0,26 & $-0,09$ \\
Cobre & $-0,06$ & 0,26 & $-0,08$ & $-0,23$ & 0,25 \\
Molibdênio & 0,27 & 0,18 & $-0,50$ & 0,13 & 0,07 \\
Ferro & 0,25 & $-0,34$ & 0,20 & $-0,15$ & $-0,06$ \\
Manganês & $-0,49$ & 0,47 & 0,03 & 0,32 & 0,42 \\
\hline
\end{tabular}

(+) - significativo ao nível de $95 \%$ de probabilidade. $(++)$ - significativo ao nível de $99 \%$ de probabilidade. 
